\title{
Vibration damping in road bridges - two case studies of full scale experiments
}

\author{
Daniel Szynal ${ }^{1, *}$, and Lucjan Janas ${ }^{1}$ \\ ${ }^{1}$ Rzeszow University of Technology, The Faculty of Civil and Environmental Engineering \\ and Architecture, 35-959 Rzeszów, Poland
}

\begin{abstract}
The paper presents the results of a vibration damping analysis of two road viaducts. The analysis was based on displacement signals recorded during the dynamic load tests carried out before an acceptance process of the viaducts. To create an additional excitation, a $5 \mathrm{~cm}$ high threshold was located on the road during low-velocity passages. The Logarithmic Decrement (LD) was calculated using an exponential curve fit to free vibration amplitudes. A fundamental frequency of vibration was considered. To minimize the influence of signal imperfections, a filtration process was carried out using bandpass Infinite Impulse Response (IIR) Bessel filter. The results were correlated for various degrees of excitation resulting from different velocities of loading vehicles and the presence of the threshold. Examples of appropriate and inadequate signals for the damping analysis were shown.
\end{abstract}

\section{Introduction}

Damping is one of the major issues describing dynamic behaviour of a structure. In contrast to other parameters, like mass and stiffness, the knowledge about it is still limited. It is obvious that a bigger damping level is better for a structure. Damping has an impact on safety, durability, and exploitation comfort of a structure. Too low damping can cause excessive vibrations that can affect the durability of the structure and the comfort of use - especially in light structures. In some cases a special damping devices have to be installed to decrease vibrations of the structure.

Bridge standards and regulations do not define the particular requirements for damping level. Lower limits of damping ratio for calculation purposes in the railway bridges dynamic analysis are presented in the standard [1]. It is also noted that effects of maximum dynamic load (peak response of a traffic speed corresponding to resonant loading) are highly dependent upon damping.

The precise evaluation of damping during a design phase is practically impossible. Estimating formulas for damping level in footbridges are known [2], although calculated

\footnotetext{
*Corresponding author: d.szynal@prz.edu.pl
} 
values are marked with high uncertainty. For this reason, many experimental researches of damping level in footbridges are being made $[3,4,5,6]$. The case is more complicated for road bridges. Due to a development of these structures, the issue acquires significance.

The damping phenomenon depends on many factors including type of a structure, degree of freedom, static scheme, types of materials, connections, and bearings. Furthermore, damping cannot be determined as a parameter, which permanently and univocally typify a relevant structure. A damping level varies depending on a vibration frequency, temperature or degree of vibration excitation. On this account, damping cannot be described by the simple physical equations used in the civil engineering. During a design phase it is advised to rely on the existing structure experiences gained through experimental tests.

This paper presents a damping research of two road viaducts. The analysis was based on displacement signals recorded during dynamic load tests.

\section{Measures expressing a level of damping}

The most popular measure expressing a level of damping, mainly because of its simplicity, is the Logarithmic Decrement (LD). There are several methods of computing provided it in the literature. One of the basic and most commonly used is the equation (1):

$$
\delta=\frac{1}{m} \ln \frac{A_{n}}{A_{n+m}}
$$

where $A_{n}$ and $A_{n+m}$ signify value of the first and last amplitude of analysed signal, respectively.

Usually, ten first amplitudes are considered [7]. In this paper, LD was calculated by a method basing on the exponential curve fit to vibration amplitudes, which is recommended by the standard [8] and widely described in [7], among others. After determining the parameters of the curve depicted by the equation $(2), \mathrm{LD}(\delta)$ is computed as a multiplication of $\beta$ and period $\mathrm{T}$ as shown in equation (3):

$$
\begin{gathered}
y=A_{0} e^{-\beta x} \\
\delta=\beta \cdot T
\end{gathered}
$$

where $\mathrm{A}_{0}$ signifies value of the initial amplitude.

Another commonly used measure of damping is the damping ratio. A relationship between LD and damping ratio is expressed by the equation (4):

$$
\zeta=\frac{\delta}{2 \pi}
$$

\section{Test procedure and signal analysis}

The structure displacement signals during dynamic load test were measured by inductive transducers with the $0,01 \mathrm{~mm}$ resolution. The measuring equipment was 
calibrated in an accredited laboratory. The test procedure was verified by a comparative research [9]. The vibration signals were recorded with the $200 \mathrm{~Hz}$ frequency. Several passages of the loading vehicle at $10,30,40$, and $50 \mathrm{~km} / \mathrm{h}$ on an even road (fig. 1a), and a passage over the $5 \mathrm{~cm}$ high threshold at 5 or $10 \mathrm{~km} / \mathrm{h}$ were recorded to implement an additional excitation [10] (fig. 1b). Because of the shape of the road near the viaduct, higher velocities could not be reached.

a)

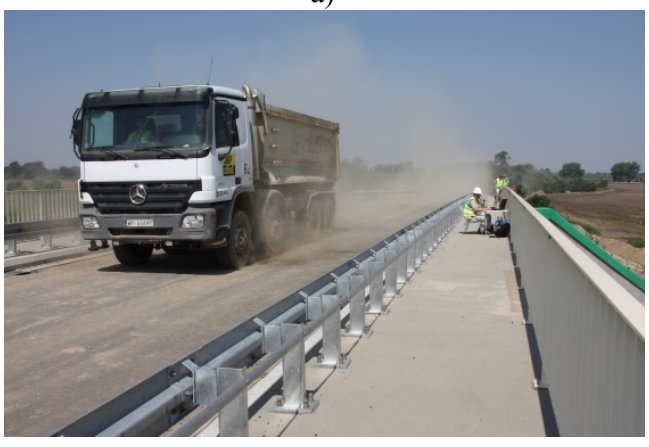

b)

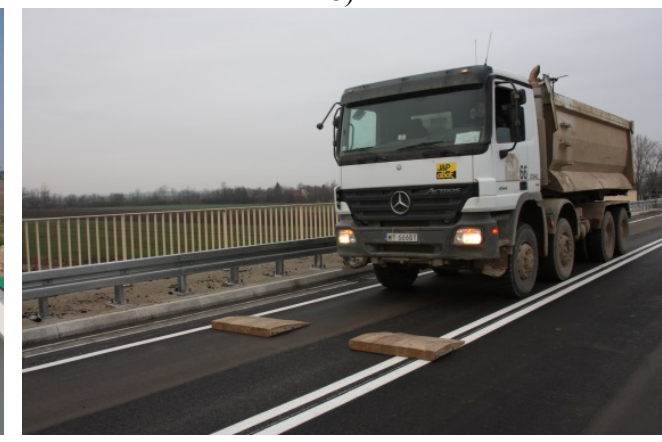

Fig. 1. A passage of the loaded truck during a dynamic load test: a) on the even road, b) over the $5 \mathrm{~cm}$ high threshold.

The signals suitable for the damping analysis were separated from the results of field test. Usefulness of the signal depends on several factors, including a degree of vibration excitation, level of noise or number of modal shapes excited during a passage. Since the calculated values of LD cannot be compared and verified with any other sources, it is necessary to choose the signals with least probability of inaccuracy. In the damping analysis, only free vibration of the structure is considered, i.e. when the last axle of the vehicle leaves the structure. Then, no additional sources of excitation resulting from the truck influence are present. Furthermore, a presence of the vehicle mass on the structure causes an excess damping factor, which would inflate the value of LD. After the extraction of free vibration signal, its suitability for the damping analysis is assessed. The beginning of free vibration was determined based on the time of passage on the viaduct.

Recorded signals are rarely suitable for the damping analysis without prior processing because of the occurring noise and interference or excitation of more than one modal shape. These issues affect the accuracy of exponential curve fit. To minimize the influence of signal imperfections, a filtration process was carried out. In this paper, a bandpass type infinite impulse response (IIR) filter was applied. After detrmining the fundamental frequency by analysing the vibration spectrum, a lower and upper cut-off frequencies were set. A vibration beyond the defined scope is separated from the signal. During the process of filtration, the signal will unavoidably change due to phenomena like a phase lag or lowering the values of initial amplitudes. The level of deformation depends on the type of applied filter, its order, and bandwidth. The higher row and narrower bandwidth, the greater deformations in the output signal. In the case of LD analysis, it is recommended to use the Bessel filter [11]. The analysis of two road viaducts presented in this paper was carried out using filter bandwidth broader than $2 \mathrm{~Hz}$ and order not higher than 5 . 


\section{Results of research}

\subsection{W-1 beam viaduct}

The first of analysed structures, marked as W-1, is a two-span beam viaduct with a continuous beam static scheme (fig. 2). Both spans are $30 \mathrm{~m}$ long. The superstructure is designed as two post-tensioned trapezium girders monolithically connected with a reinforced concrete deck slab. The substructure consists of U-shaped abutments and a pier made of two separate columns, one under each girder. The viaduct is at an angle of $84.11^{\circ}$ to the highway below it. The span structure is supported on the substructure by means of elastomeric bearings. The supports are bedded on shallow foundations made of reinforced concrete footings. The viaduct was designed in compliance with the A class according to the standard [12]. The $\mathrm{W}-1$ viaduct is a typical structure in case of modern bridge structures currently built above highways.



Fig. 2. The construction scheme of the W-1 viaduct with indicated measurement points.

Six signals selected for the analysis had at least ten amplitudes with the values no less than resolution of the inductive transducers used during the field test, i.e. $0.01 \mathrm{~mm}$. The figures $3 \mathrm{a}$ and $3 \mathrm{~b}$ present the signal inadequate for the damping analysis because of the low excitation, and the appropriate signal with relatively high excitation, respectively.

a)

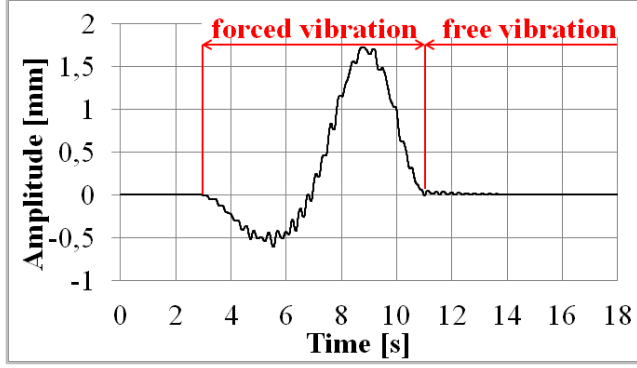

b)

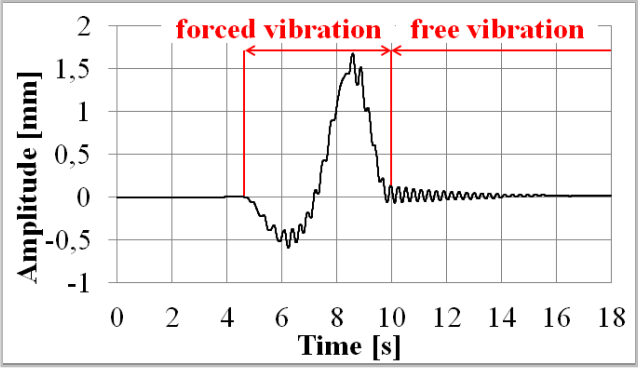

Fig. 3. The examples of measured signals: a) low excitation, inadequate for the damping analysis b) relatively high excitation - appropriate for the damping analysis. 
After extracting the free vibration range, the signal was filtrated. From the processed signal, the values of successive amplitudes were determined. The exponential curve was fit by means of a least-squares method excluding the initial amplitudes of values lowered by the filtration process. After determining the exponential curve parameters and period of vibration, LD was calculated. The figures $4 \mathrm{a}$ and $4 \mathrm{~b}$ present the filtered vibration with curve fit, and vibration spectrum, respectively.

a)

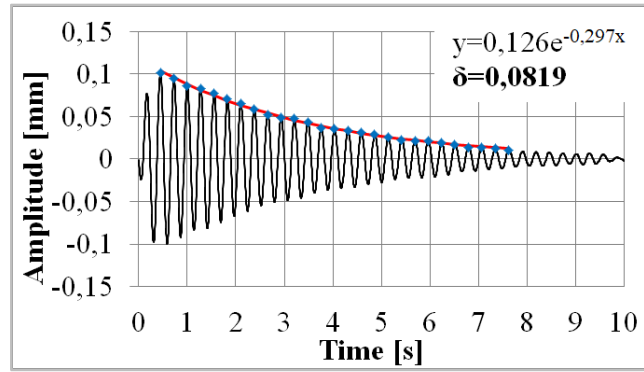

b)



Fig. 4. The vibration damping analysis for a passage at a velocity of $40 \mathrm{~km} / \mathrm{h}$ in the B direction: a) free vibrations and exponential curve fit to the vibration amplitudes, b) vibration spectrum.

The calculated values of LD and damping ratio for vibration with the fundamental frequency $\mathrm{f}=3,63 \mathrm{~Hz}$ are presented in table 1 . The mean value of $\mathrm{LD}$ is 0.088 and matches the average damping according to [11], which is typical for most bridges and viaducts $(0.05<\delta<0.15)$.

Table 1. The values of LDT and damping ratio for $\mathrm{W}-2$ viaduct.

\begin{tabular}{|c|c|c|c|c|}
\hline $\begin{array}{c}\text { Velocity/direction } \\
\text { of passage }\end{array}$ & $\begin{array}{c}\text { Measurement } \\
\text { point }\end{array}$ & $\begin{array}{c}\text { Initial } \\
\text { amplitude [mm] }\end{array}$ & LD & $\begin{array}{c}\text { Damping } \\
\text { ratio }\end{array}$ \\
\hline \multirow{2}{*}{$30 / \mathrm{A}$} & P1 & 0,015 & u.c. & u.c. \\
\hline & $\mathrm{P} 2$ & 0,013 & u.c. & u.c. \\
\hline \multirow{2}{*}{$40 / \mathrm{A}$} & $\mathrm{P} 1$ & 0,021 & u.c. & u.c. \\
\hline & $\mathrm{P} 2$ & 0,020 & u.c. & u.c. \\
\hline \multirow[b]{2}{*}{$40 / B$} & $\mathrm{P} 1$ & 0,019 & u.c. & u.c. \\
\hline & $\mathrm{P} 2$ & 0,022 & u.c. & u.c. \\
\hline \multirow{2}{*}{$50 / \mathrm{B}$} & $\mathrm{P} 1$ & 0,101 & 0,097 & 0,015 \\
\hline & $\mathrm{P} 2$ & 0,087 & 0,082 & 0,013 \\
\hline \multirow{2}{*}{ 10/A (threshold) } & P1 & 0,041 & 0,082 & 0,013 \\
\hline & $\mathrm{P} 2$ & 0,043 & 0,087 & 0,014 \\
\hline \multirow{2}{*}{ 10/B (threshold) } & $\mathrm{P} 1$ & 0,101 & 0,099 & 0,016 \\
\hline & $\mathrm{P} 2$ & 0,970 & 0,083 & 0,013 \\
\hline \multicolumn{3}{|r|}{ Mean value: } & $\overline{0,088}$ & 0,014 \\
\hline \multicolumn{3}{|r|}{ Standard deviation: } & 0,007 & 0,001 \\
\hline
\end{tabular}

u.c. - unable to calculate LD due to the low excitation of the construction

\subsection{W-2 frame viaduct}

The second analysed viaduct, marked as W-2, is a three-span frame structure (fig. 5). The structure of side spans is designed as a post-tensioned concrete slab. The middle span is made of two post-tensioned trapezium girders monolithically connected with a reinforced concrete deck slab. The viaduct is shaped at an angle of $62.1^{\circ}$ towards the obstacle. The soil 
under the shallow foundation of the structure was strengthened by means of the DSM technology. The viaduct was designed in compliance with the A class according to the standard [12].

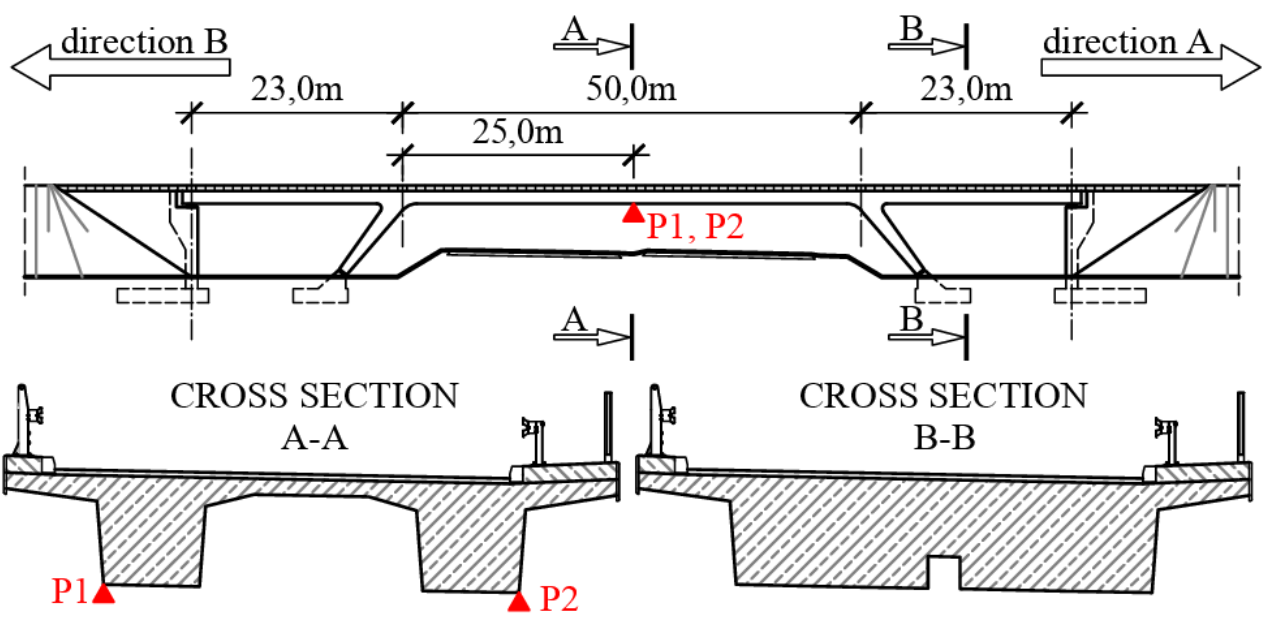

Fig. 5. The construction scheme of the W-2 viaduct with indicated measurement points.

For the damping analysis of the W-2 viaduct, ten signals were selected. Despite the high excitation, the signals which were acquired during the passage over the threshold located in the middle span had to be rejected. Before the last axle of loading vehicle left the structure, the vibrations dissipated (fig. 6a). As anticipated, the appropriate free vibration signal was recorded during the passage over the threshold located in the side span (last span in driving direction) - fig. 6b. The example of $\mathrm{LD}$ analysis for the $\mathrm{W}-2$ viaduct is presented in the figures $7 \mathrm{a}$ and $7 \mathrm{~b}$. The results of calculations for the fundamental frequency $\mathrm{f}=2.83$ $\mathrm{Hz}$ are shown in the table 2.

a)



b)



Fig. 6. The signal analysis for passages with the threshold located on the road: a) threshold in the middle span, b) threshold in the side span. 
a)



b)

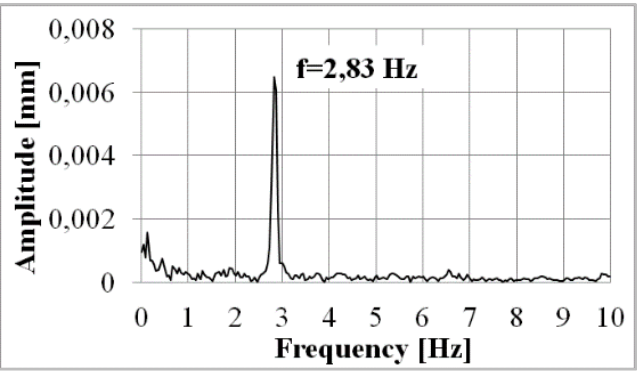

Fig. 7. The vibration damping analysis for a passage at a velocity of $40 \mathrm{~km} / \mathrm{h}$ in the A direction: a) free vibrations and exponential curve fit to the vibration amplitudes, b) vibration spectrum.

Table 2. The values of LDT and damping ratio for the $\mathrm{W}-2$ viaduct.

\begin{tabular}{|c|c|c|c|c|}
\hline $\begin{array}{c}\text { Velocity/direction } \\
\text { of passage }\end{array}$ & $\begin{array}{c}\text { Measurement } \\
\text { point }\end{array}$ & \begin{tabular}{|c|} 
Initial \\
amplitude [mm]
\end{tabular} & LD & $\begin{array}{c}\text { Damping } \\
\text { ratio }\end{array}$ \\
\hline \multirow{2}{*}{$30 / \mathrm{B}$} & $\mathrm{P} 1$ & 0,010 & u.c. & u.c. \\
\hline & $\mathrm{P} 2$ & 0,009 & u.c. & u.c. \\
\hline \multirow{2}{*}{ 40/A (passage 1) } & $\mathrm{P} 1$ & 0,191 & 0,128 & 0,021 \\
\hline & $\mathrm{P} 2$ & 0,185 & 0,132 & 0,022 \\
\hline \multirow{2}{*}{ 40/A (passage 2) } & $\mathrm{P} 1$ & 0,146 & 0,137 & 0,020 \\
\hline & $\mathrm{P} 2$ & 0,152 & 0,147 & 0,021 \\
\hline \multirow{2}{*}{ 50/B (passage 1) } & $\mathrm{P} 1$ & 0,128 & 0,141 & 0,022 \\
\hline & $\mathrm{P} 2$ & 0,123 & 0,154 & 0,023 \\
\hline \multirow{2}{*}{ 50/B (passage 2) } & $\mathrm{P} 1$ & 0,162 & 0,133 & 0,022 \\
\hline & P2 & 0,171 & 0,136 & 0,025 \\
\hline \multirow{2}{*}{$\begin{array}{l}\text { 5/A (threshold in the } \\
\text { side span) }\end{array}$} & $\mathrm{P} 1$ & 0,038 & 0,135 & 0,021 \\
\hline & $\mathrm{P} 2$ & 0,038 & 0,140 & 0,022 \\
\hline \multirow{2}{*}{$\begin{array}{l}10 / \mathrm{A} \text { (threshold in } \\
\text { the middle span) }\end{array}$} & P1 & 0,013 & u.c. & u.c. \\
\hline & $\mathrm{P} 2$ & 0,014 & u.c. & u.c. \\
\hline \multicolumn{3}{|r|}{ Mean value: } & $0, \mathbf{0 , 1 3 8}$ & $\begin{array}{l}0,022 \\
\end{array}$ \\
\hline \multicolumn{3}{|r|}{ Standard deviation: } & 0,007 & 0,001 \\
\hline
\end{tabular}

u.c. - unable to calculate LD due to the low excitation of the construction

\section{Summary and conclusions}

The results presented in the paper indicate the damping level of two viaducts, which substructures are made of the post-tensioned concrete. The first viaduct is a typical modern two-span structure consisting of two trapezium girders in the static scheme of continuous beam. Second viaduct is a frame structure.

The values of logarithmic decrement and damping ratio were calculated using the curvefitting approach adopting the least-squares method. The analysis was carried out basing on the displacement signals recorded during dynamic load tests of the viaducts. The signals with amplitudes lower than accuracy of the measurement equipment were rejected from the calculations.

The analysis indicates that not all signals recorded during field tests can be used to determine the level of damping - even if the excitation of forced vibration is high. In some cases, higher excitation of free vibration was noted during passages without the threshold located on the road. Vibration induced by the vehicle driving over the threshold often 
declines before last axle of the truck leaves the structure. It is caused by the low passage velocity. This problem occurs in the results of the W-2 viaduct dynamic load test (fig. 6a, table 2).

The determined values of $\mathrm{LD}$ varies from 0.82 to 0.99 for viaduct $\mathrm{W}-1$ and from 0.128 to 0.154 for W-2. Differences in the estimation of damping for individual bridges result from the non-linearity of the phenomenon - e.g. the level of damping depends on the level of vibration. The mean values of LD for the analysed viaducts amount 0.088 for W- 1 and 0.138 for W-2. The damping level of both constructions is acceptable - the viaducts can by assigned to an average damping group.

\section{References}

[1] CEN, EN 1991-2 - Eurocode 1: Actions on structures, part 2: traffic loads on bridges, European Committee for Standardisation, Brussels, (2003)

[2] M. Schlaich, K. Brownlie, J. Conzett et al,. fib Bulletin 32: Guidelines for the design of footbridges (Stuttgart: Sprint - Digital - Druck and fib) FIB, (2005)

[3] M. Pańtak, B. Jarek, K. Marecik, Vibration damping in steel footbridges, IOP Conf. Series: Materials Science and Engineering 419, (2018)

[4] T. Siwowski, L. Janas: Numerical and experimental assessment of the dynamic behaviour of a circular footbridge, Proceedings of the International Conference on Structural Dynamic, EURODYN,2014-January, 1297-1302, (2014)

[5] P. Hawryszków, R. Pimentel, F. Silva, Vibration effects of loads due to groups crossing a lively footbridge, Procedia Engineering, 199, 2808-2813, (2017)

[6] G. Poprawa, M. Salamak, P. Klikowicz, Dynamic identification of composite beam pedestrian bridges, Advances and Trends in Engineering Sciences and Technologies II - Proceedings of the 2nd International Conference on Engineering Sciences and Technologies, ESaT 2016, 231-236, (2017)

[7] P. Olaszek, Cyfrowe metody pomiarowe $w$ zastosowaniu do badań mostów, Komitet Inzynierii Ladowej i Wodnej PAN, Warsaw, (2015)

[8] ISO 18649 Mechanical vibration - Evaluation of measurement results from dynamic tests and investigations on bridges, (2004)

[9] P. Olaszek, L. Janas, M. Salamak, A. Matysek, Badania porównawcze przyspieszeń i przemieszczeń konstrukcji mostowych pod próbnym obciążeniem dynamicznym, Drogownictwo, 10, 339-343, (2014)

[10] P. Olaszek, M. Łagoda, J. R. Casas, Diagnostic load testing and assessment of existing bridges: Examples of application, Structure and Infrastructure Engineering, 10, 834842, (2014)

[11] M. Salamak, Experimental methods for determining the level of vibration damping in footbridges, Silesian University of Technology, Faculty of Civil Engineering, (2003)

[12] PN-85/S-10030 Obiekty mostowe - obciążenia, (1985) 